\title{
Trace-element chemistry of non-marine ostracod shells: a preliminary evaluation of cleaning methods.
}

\author{
JONATHAN A. HOLMES \\ School of Geography, \\ Kingston Polytechnic, U.K.
}

Trace-element analysis of ostracod shells has been shown to be a powerful tool in Quaternary palaeoenvironmental reseach (e.g. Chivas et al., 1986). Particular use has been made of $\mathrm{Sr} / \mathrm{Ca}$ and $\mathrm{Mg} / \mathrm{Ca}$ ratios in ostracod shells as palaeosalinity and palaeotemperature indictors. However, work on trace elements such as $\mathrm{Cd}, \mathrm{Zn}, \mathrm{Cu}$ and $\mathrm{Ba}$ in benthic foraminifera (e.g, Boyle, 1981) has shown that chemical cleaning of the shell is necessary to remove surface-bound contaminants, so that only the latticebound elements are analyzed. This note describes the application of selected cleaning methods to non-marine ostracod shells and evaluates their effect on shell chemistry with particular reference to $\mathrm{Sr}, \mathrm{Mg}, \mathrm{Mn}$ and Fe.

Samples of ostracod shells were taken from late Quaternary lacustrine marls from Wallywash Great Pond, Jamaica. Adult valves of the genus Cypretta Vàrva 1895 were selected at random and subjected to one of three cleaning methods as follows.

Method A: shells cleaned thoroughly with a clean nylon paint brush $(0000)$ and deionised water, until all visible particles (under x40 magnification) had been removed. Shells cleaned by methods $B$ and $C$ were also initially treated in this way.

Method B: shells cleaned in a basic hydroxylamine hydrochloride solution at $80^{\circ} \mathrm{C}$ for 30 minutes and then rinsed in deionised water (Boyle, 1981).

Method C: shells cleaned in a basic sodium dithionite complexing reagent at $80^{\circ} \mathrm{C}$ for 30 minutes and then rinsed with deionised water (Boyle, 1981).

Nine individual valves were cleaned using each method. Once cleaned, the valves were individually dissolved in $3 \mathrm{ml}$ of $5 \% \mathrm{v} / \mathrm{v}$ Aristar $\mathrm{HCl}$ and the resulting 27 solutions analyzed for $\mathrm{Ca}, \mathrm{Sr}, \mathrm{Mg}, \mathrm{Mn}$ and Fe using a JY-70 plus ICP-AES. Corrections were made for contaminants in the solvent acid and for machine drift. Results were expressed as molar $\mathrm{M} / \mathrm{Ca}$ ratios following Chivas et al. (1986). Using one-way ANOVA, no significant difference was found in $\mathrm{Sr} / \mathrm{Ca}, \mathrm{Mg} / \mathrm{Ca}$ or $\mathrm{Fe} / \mathrm{Ca}$ between cleaning methods at the $1 \%$ significance level. For $\mathrm{Mn} / \mathrm{Ca}$, a significant difference was found, although the largest $\mathrm{Mn} / \mathrm{Ca}$ ratio occurred with the most intense cleaning method (method C). This is in contrast to Boyle (1981) whose results, albeit for different elements, indicated that the more intense cleaning method lowered the $\mathrm{M} / \mathrm{Ca}$ ratio as surface contaminant was progressively removed.

The mean shell weight of the ostracod valves, calculated using the Ca content of the analytical solutions, showed a marked difference between cleaning methods, being especially low for method $C$. Although adult ostracod shells do vary naturally in weight, the mean weight of shells cleaned by method $C(14.5 \pm 8.2 \mu \mathrm{g})$ is only about half that of those subjected to method A $(27.8 \pm 4.8 \mu \mathrm{g})$. Shells cleaned by method $\mathrm{B}$ have a slightly lower mean weight $(25.7 \pm 8.4 \mu \mathrm{g})$. These results suggest that cleaning method $C$ in particular removes the outer surface of the ostracod shell leading to a significant weight loss.

These results indicate that the removal of the outer layer of shell has no significant effect on the $\mathrm{M} / \mathrm{Ca}$ ratio for $\mathrm{Sr}, \mathrm{Mg}$ or Fe suggesting that these elements may be distributed fairly uniformly within the shell. However, this suggestion contrasts with the work of Cadot et al. (1972), who found marked variations in $\mathrm{Mg}$ within the shells of marine ostracods. For $\mathrm{Mn}$, cleaning of the shell with method $C$ appears to strip off a layer of low Mn/Ca calcite at the surface. Whereas brush cleaning is the best method for $\mathrm{Sr}, \mathrm{Mg}$ and $\mathrm{Fe}$, results are inconclusive for $\mathrm{Mn}$, although the use of method $\mathrm{C}$ would give misleading ratios. Further experiments are required with larger sample sizes, different species and specimens from different types of sediment matrix in order to assess the wider implications of these findings. However, the preliminary results suggest that brush cleaning is adequate for microchemical work on ostracod shells involving $\mathrm{Sr}, \mathrm{Mg}$ and Fe.

\section{REFERENCES}

Boyle, E. 1981. Cadmium, zinc, copper and barium in foraminifera tests. Earth and Planetary Science Letter. .53, 11-35.

Cadot, H.M., van Schmus, W.R. \& Kaesler, R.L. 1972. Magnesium in calcite of marine Ostracods. Bulletin of the Geological Society of America. 83, 3519-3522.

Chivas, A.R., de Deckker, P. \& Shelley, J.M.G. 1986. Magnesium and strontium in non-marine ostracod shells as indicators of palaeosalinity and palaeotemperature. Hydrobiologia. 43, 135-142. 